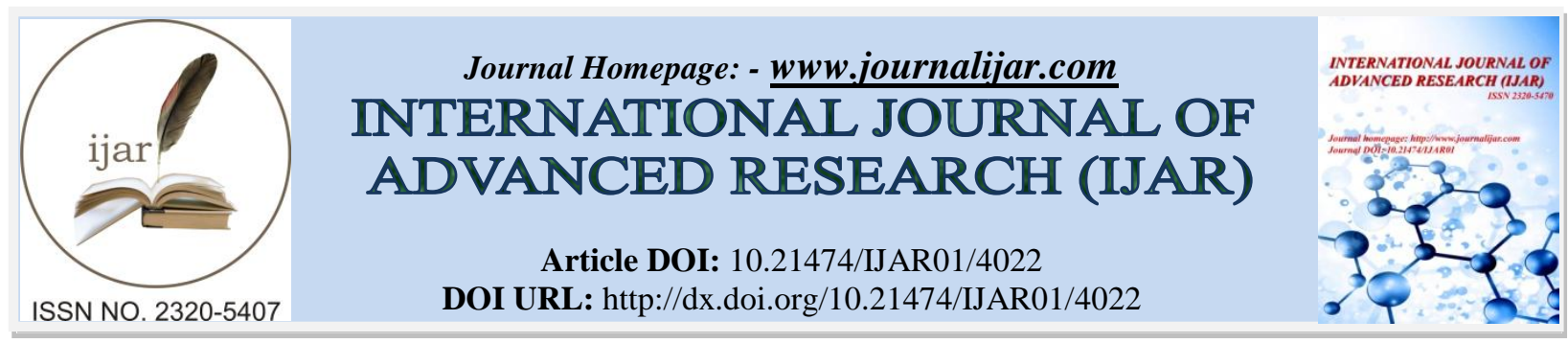

RESEARCH ARTICLE

\title{
HISTOPATHOLOGICAL, BIOCHEMICAL AND HAEMATOLOGICAL CHANGES OF NALBUPHINE- HCL ADMINISTRATION ON LIVER OF ALBINO RAT.
}

Ashraf Yahya Albarakai.

Human Anatomy Department, College of Medicine, Taif University, Saudi Arabia.

\section{Manuscript Info}

Manuscript History

Received: 25 February 2017

Final Accepted: 17 March 2017

Published: April 2017

Key words:-

Liver, Histopathology, Nalbuphine-

HCL, Opioids, Liver enzymes,

Hematological parameters.

\section{Abstract}

Nalbuphine- $\mathrm{HCl}$ is a semi-synthetic opioid agonist-antagonist used commercially as an analgesic under a variety of trade names, including Nubain and Manfine. Nalbuphine- $\mathrm{HCl}$ considers one of the widely used opioids in recent years is an effective analgesic agent for the treatment of moderate to severe pain. So, this study was designed to study toxicity of Nalbuphine- $\mathrm{HCl}$ on liver. The animals were divided into four groups, twenty animals in each group. The treated groups were injected with the analgesic, double and tribal doses with Nalbuphine$\mathrm{HCl}$, respectively. The negative group animals were injected only with the same of saline $(0.9 \% \mathrm{NaCl})$. The main histopathological findings were showed inflammatory cellular infiltration, dilated congested blood vessels, hydropic degeneration, and fibrotic regions around the proliferated bile ducts. Also, pyknotic and karyolitic nuclei were detected. In addition, the biochemical results of the liver function (AST, ALT and ALP) and the hematological investigation ( $\mathrm{Hb}, \mathrm{RBC}$ HCT and the platelets cells) revealed a marked decrease in liver enzymes and hematological parameters, which were parallel to the histopathological changes after the treatment with all doses of Nalbuphine-HCl.

Copy Right, IJAR, 2017,. All rights reserved.

\section{Introduction:-}

Although, opioids are different in their chemical structure, analgesic potency and in their potential. But, they have basically similar pharmacologic profiles (Das and Ratty 1987). Opioid analgesics such as morphine, meperidine and fentanyl are frequently used for the management of clinical pain (Walker, Butelman et al. 1993). These drugs interact with specific opioid receptors (i.e. $\mu$ receptors) in the central nervous system and exhibit potent analgesic activities (Liaqat and Dar 2016). However, all these opioids analgesics have similar disadvantages. For long-term use, addiction is the most unwanted problem. Severs respiratory depression can also occur in some patients (Gerak, Butelman et al. 1994). Nalbuphine- $\mathrm{HCl}$ is semi-synthetic analgesics opioids, and it is consider an effective analgesic agent for the treatment of mild to moderate pains (Miller 1980, Pick, Paul et al. 1992). Nalbuphine-HCl is well narcotic drugs and effectively used in post-operative analgesic for labor analgesia (Liaqat and Dar 2016). Liver play a pivotal role in body metabolism, due to the fact that hepatocytes play a key role in detoxify any toxic substances that present in the blood, and protein synthesis (Holm and Kasper 1985). The commonly used liver function tests primarily, for assess liver injury. Indeed, the blood test may reflect problem increases enzymes of the liver functions (alanine aminotransferase "ALT", aspartate aminotransferase "AST" and alkaline phosphatase "ALP") and harmful effects on the blood picture when the animals treated with morphine (Rosow, Moss et al. 1982, Pacifici, Bencini et 
al. 1986, William, Sekar et al. 1991, Borzelleca, Egle et al. 1994, Mescher 2013). In addition, in some studies that treatment of experimental animals with morphin or tramadol for few weeks can be induced many histopathological changes of the hepatic tissues. Light microscopy for these studies revealed severe centrilobular congestion, portal fibrosis with bile ductal proliferation and an increased inflammatory infiltration and focal parenchymal necrosis (Bekheet 2010, Alsbery 2016).

Pharmaceutically, pure opioid agonists are not considered to be good candidates for the preparation of long-acting formulations because of safety considerations. Pure opioids agonists such as morphine and fentanyl can cause severe respiratory depression in high doses, without a ceiling effect. It is a problem if a large amount of drug is accidentally released from the formulation into the blood stream. In contrast, mixed opioid agonist-antagonist as $\mathrm{Nalbuphine- \textrm {HCl }}$ are relatively safer and have a ceiling effect on respiratory depression (Gerak, Butelman et al. 1994).

In this regards, some studies have also shown that the effect treatment with the analgesic, double and triple doses of Nalbuphine-HCl, can be induce histopathological changes in lung of the experimental animals (El-Bakry, Kandil et al. 1995). Also, the analgesic dose of Nalbuphine- $\mathrm{HCl}$ for 15 and 30 day can be induce deleterious alterations in their changes on the hematological and biochemical analysis (Al-Shinnawy 2009). In addition, there are many studies have shown the toxic effects of the analgesic dose of Nalbuphine- $\mathrm{HCl}$ for a weeks or a months on the hepatic tissues or on the blood picture when the animals treated with Nalbuphine-HCl (Pick, Paul et al. 1992, El-Bakry, Kandil et al. 1995, Chen, Hu et al. 2002, Chu, Wang et al. 2003, Al-Shinnawy 2009, Attia, Kamel et al. 2015).

In contrast, there are no recent studies to indicate to the effects of double and triple doses of Nalbuphine-HCl doses of liver tissue, so this study was designed to study toxicity of Nalbuphine- $\mathrm{HCl}$ on liver.

\section{Materials and Methods:-}

Nalbuphine- $\mathrm{HCl}$ is a sterile solution available in ampoules of $1 \mathrm{ml}$ containing $20 \mathrm{mg}$ of $\mathrm{Nalbuphine-HCl}$ was purchased from Amoun Pharmaceutical Co. (S.A.E, Cairo, Egypt).

\section{Experimental Animals:-}

Healthy adult albino rat approximately 3-4 months old and each weight from 200-250 gm. Animals were housed in specially designed cages and kept in the laboratory under the same standard conditions for at least one week for acclimatization before experimentation. Animals were obtained from Taif University, Saudi Arabia.

\section{Dose and Animal groups:-}

Eighty animals were used for experimental study. The animals were divided into four groups, twenty animals for each group.

First (control) group:- Animals were injected with normal saline $(0.9 \% \mathrm{NaCl})$, by intraperitoneal injection for 30 days.

Second group:- Animals were injected with analgesic dose (0.0009 mg/gm B.W.), by intraperitoneal injection for 30 days.

Third group:- Animals were injected with double analgesic dose (0.0018 mg/gm B.W.), by intraperitoneal injection for 30 days.

Fourth group:- Animals were injected triple analgesic dose $(0.0027 \mathrm{mg} / \mathrm{gm} \mathrm{B.W.})$, by intraperitoneal injection for 30 days.

All the doses in this experiment were calculated according to Paul et al (1992).

Biochemical and haematological preparation:-

Blood samples were collected for biochemical and haematological analysis from the hearts of rats in all groups on the last day of the experiment and divided into two samples:

First sample:- The separate serum samples were centrifuged at 3000 rounds for 10 minutes to assayed AST, ALT and ALP: 
A. Aspartate aminotransferase was assayed by mixing the serum to buffered solution of L- aspartic acid and 2ketoglutarate and then incubated for one hour at $37^{\circ} \mathrm{C}$. After incubation, $1 \mathrm{~mm}$ of DNPH and $0.4 \mathrm{~m} \mathrm{of} \mathrm{NaOH}$ was added (Clough 1982).

B. Alanine aminotransferase was assayed by mixing the serum to buffered solution of DL- alanine and 2ketoglutarate, and then incubated for thirty minutes at $37^{\circ} \mathrm{C}$. After incubation, $1 \mathrm{~mm}$ of DNPH and $0.4 \mathrm{~m}$ of $\mathrm{NaOH}$ was added (Daniel and Marshall 1999).

C. Alkaline phosphatase was assayed by using p- nitrophenol phosphate as substrate, in alkaline buffer with fresh unhemolysed serum for $45 \mathrm{~min}$ at $12{ }^{\circ} \mathrm{C}$ (Daniel and Marshall 1999).

\section{Second sample:-}

Blood samples were collected on EDTA to estimate mean total red cells and total white cells count and platelets were determined by use haemocytometer. In addition the blood films were stained by Giemsa stain for differential leucocytic count. Mean haemoglobin concentration was determined as described by Lutz and Dzik (1993) using haemoglobinometer, whereas total red cells and total white cells count and platelets were determined by the use of haemocytometer (Lutz and Dzik 1993).

\section{Histological preparation:-}

Animals were dissected and their livers were removed. For histological preparations, the livers was fixed immediately after collection in $10 \%$ neutral buffered formalin for 24 hours, and then embedded in paraffin wax. Paraffin sections of 5 microns thickness were prepared and stained with Ehrlich's haematoxylin (H) and eosin (E) (Bancroft and Gamble 2008).

\section{Statistical Analyses:-}

The data obtained from the biochemical and haematological analyses of different groups were presented in the Tables $1 \& 2$ as Mean \pm standard error. The significance of differences between mean values was determined using Chi-Square test and independent sample T-test for comparisons. P $<0.05$ represents level of significance (SPSS ${ }^{2} 4$ Inc., USA).

\section{Ethical Considerations:-}

Under anesthesia is done during painful procedures to avoid distress and pain. By applicable international laws and regulations our standards of animal care and administration met those required.

\section{Results:- \\ Hepatic histopathological findings:-}

The liver section of control animals showing normal hepatic structure in the cytoplasm of the hepatocytes of the control group, and most of hepatic cells contain a central rounded nucleus while some binucleated. The sinusoidal endothelium is formed of endothelial lining cells and the phagocytic kupffer cell (Fig. 1). Histopathological examination of the second group showed that hydropicdegenrative changes in hepatocytes with picknotic nuclei and obliterated blood sonusoides present between the cords were detected in liver sections of rat (Fig. 2). Histopathological examination for the third group showed vaculated hepatic cells with picknotic nuclei, necrotical areas, congested and dilating central vein with hemorrhage (Fig. 3). Also, histopathological examination of the fourth group showed numerous histopathological changes in the hepatocytes exhibited marked stagnant blood in portal vein, inflammatory infiltration around the hyperplastic bile duct, vacuolated, ball owning cytoplasm with more pyknotic nuclei, more congested and dilated blood sinusoids (Fig. 4).

\section{Liver function Result:-}

The biochemical results of the liver function in the Table 1 showed that ALT values in the treated animals with analgesic dose of Nalbuphine- $\mathrm{HCl}$ in the second group was significantly $(\mathrm{P}<0.01)$ increased when compared to the first group. Aspartate aminotransferase values in the treated animals with double analgesic dose of $\mathrm{Nalbuphine- \textrm {HCl }}$ in the third group showed highly significant $(\mathrm{P}<0.001)$ increased when compared to the first group. Also, the biochemical results of ALP values in the treated animals with triple analgesic dose of Nalbuphine-HCL in the fourth group showed very highly significant $(\mathrm{P}<0.001)$ increased when compared to the first group.

\section{Complete blood count Results (CBC):-}

The hematological results in the Table 1 showed that hemoglobin values in the treated animals with analgesic dose of Nalbuphine- $\mathrm{HCl}$ in the second group was showed significantly $(\mathrm{P}<0.01)$ decreased when compared to the first 
group. The results of the $\mathrm{CBC}$ of hemoglobin values in the treated animals with double analgesic dose of Nalbuphine- $\mathrm{HCl}$ in the third group showed highly significant $(\mathrm{P}<0.001)$ decreased when compared to the first group. Also, the hematological results of hemoglobin values in the treated animals with triple analgesic dose of Nalbuphine-HCL in the fourth group showed very highly significant $(\mathrm{P}<0.001)$ increased when compared to the first group. In addition, the hematological results of RBC, HCT, platelets analysis were showed decreased in the values of RBC, HCT, and platelets when compared to the first group, significant $(\mathrm{P}<0.1)$, very significant $(\mathrm{P}<0.01)$ and very highly significant $(\mathrm{P}<0.001)$ respectively. However, the above results are revealed that effect of Nalbuphine- $\mathrm{HCl}$ on values of hemoglobin, red blood cells, haematocrit and platelet cells in all groups revealed significant decrease in comparison to those of the first group, except the white blood cells count which showed no significant changes in its value when compare all the treated groups with Nalbuphine-HCL to the control group.

The photomicrographs and comments.

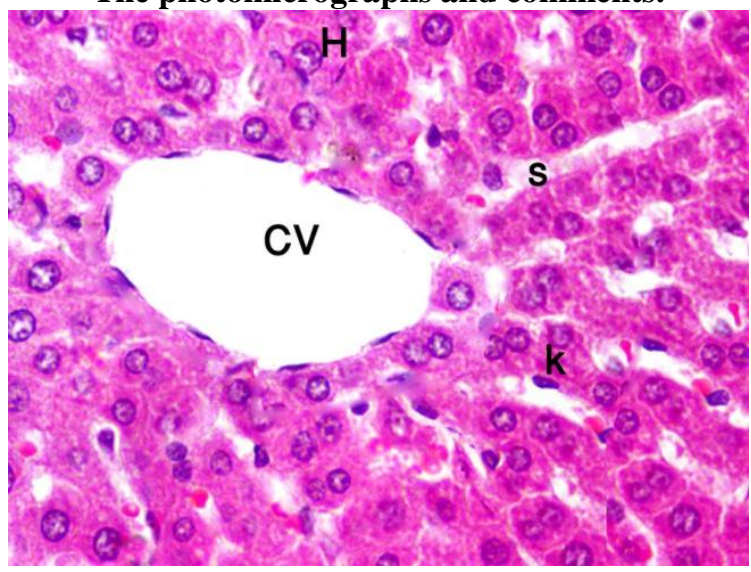

Fig. 1:- A photomicrograph of section in the liver of control group showing most of hepatic cells $(\mathrm{H})$ contains a central rounded nucleus while some binucleated. The sinusoidal endothelium is formed of endothelial lining cells and the phagocytic kupffer cell (k), (H. \& E. X 400).

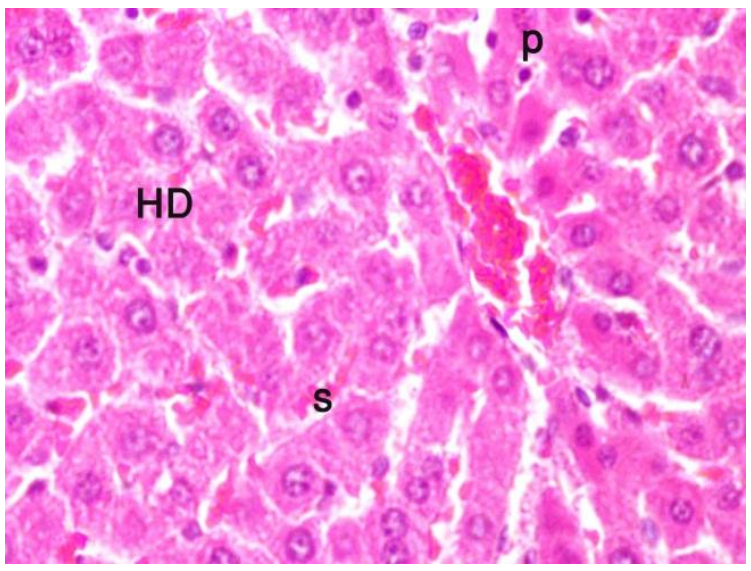

Fig. 2:- A photomicrograph of section in the liver of second group of rat treated with analgesic dose of Nalbuphine$\mathrm{HCl}$ showing hydropic degenrative (HD) changes in hepatocytes with picknotic nuclei (p) and obliterated blood sonusoides present between the cords (s), (H. \& E. X 400). 


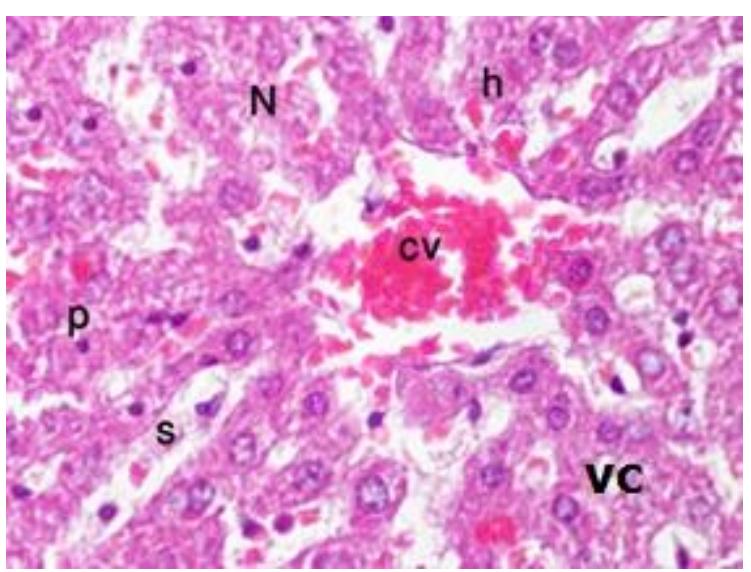

Fig. 3:- A photomicrograph of section in the liver of third group of rat treated with double analgesic dose of Nalbuphine-HCl showing vacuolated hepatic cells (vc) with picknotic nuclei (p), necrotical areas (N), congested and dilating central vein (cv), blood sinusoids (s) and hemorrhage (h), (H. \& E. X 400).

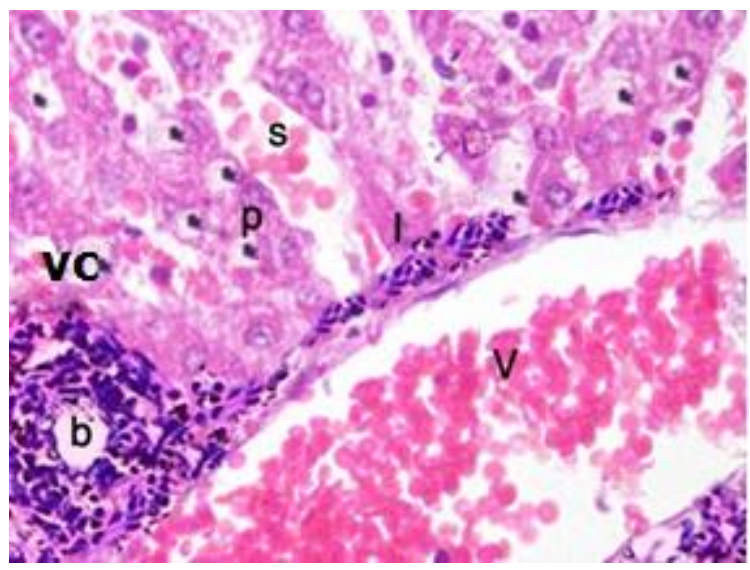

Fig. 4:- A photomicrograph of section in the liver of fourth group of rat which treated with triple analgesic dose of Nalbuphine-HCl demonstrating marked stagnant blood in portal vein (v), inflammatory infiltration (I) around hyperplastic bile duct (b), vacuolated, ball owning cytoplasm with more pyknotic nuclei (p), more congested dilated blood sinusoids (s) and vaculation (vc), (H. \& E. X 400).

Table 1:- Shows mean +SD values of rat liver function tests (ALT, AST and ALP).

\begin{tabular}{|c|c|c|c|}
\hline Groups & ALT (IU/L) & AST (IU/L) & ALP (IU/L) \\
\hline First group (control) & $34.3 \pm 6.8$ & $125.1 \pm 20.4$ & $75.8+3.3$ \\
\hline Second group & $42.0 \pm 5.1^{*}$ & $189.6 \pm 30.0^{*}$ & $88.1+3.1^{*}$ \\
\hline Third group & $58.2 \pm 5.2^{* *}$ & $257.2 \pm 20.7 * *$ & $127.2 \pm 2.7^{* *}$ \\
\hline Fourth group & $78.3 \pm 6.5^{* * *}$ & $405.1 \pm 10.5 * * *$ & $154.4 \pm 8.1^{* * *}$ \\
\hline
\end{tabular}

The data expressed as Mean \pm SD whereas: $* \mathrm{P}<0.1=$ significant, $* * \quad \mathrm{P}<0.01=$ highly significant and $* * * \mathrm{P}<$ $0.001=$ very highly significant. $\mathrm{ALT}=$ alanine aminotransferase, $\mathrm{AST}=$ aspartate aminotransferase and $\mathrm{ALP}=$ alkaline phosphatase.

Table 2:- Shows complete blood picture (hemoglobin, red blood cells, haematocrit platelets and white blood cells) values in all groups:

\begin{tabular}{|c|c|c|c|c|c|}
\hline Groups & $\mathrm{Hb}(\mathrm{g} / \mathrm{dl})$ & $\mathrm{RBC}\left(\mathrm{x} 10^{6} / \mu \mathrm{l}\right)$ & $\mathrm{HCT} \%$ & $\begin{array}{c}\text { Platelets } \\
\left(\mathrm{x} 10^{3} / \mu \mathrm{l}\right)\end{array}$ & $\begin{array}{c}\mathrm{WBC} \\
\left(\mathrm{x} 10^{3} / \mu \mathrm{l}\right)\end{array}$ \\
\hline $\begin{array}{c}\text { First (control) } \\
\text { group }\end{array}$ & $16.05 \pm 0.15$ & $5.99 \pm 0.51$ & $46.2 \pm 0.48$ & $452.29 \pm 1.96$ & $5.70 \pm 0.18$ \\
\hline Second group & $15.06 \pm 0.11^{*}$ & $4.29 \pm 0.31^{*}$ & $40.1 \pm 0.42^{*}$ & $429.29 \pm 3.60^{*}$ & $5.61 \pm 0.21$ \\
\hline Third group & $14.09 \pm 0.9^{* *}$ & $3.21 \pm 0.21 * *$ & $37.1 \pm 0.82^{* *}$ & $399.21 \pm 8.30^{* *}$ & $5.57 \pm 0.11$ \\
\hline Fourth group & $13.01 \pm 0.19^{* * *}$ & $2.11 \pm 0.11 * * *$ & $36.1 \pm 0.82^{* * *}$ & $379.42 \pm 6.32 * * *$ & $5.57 \pm 0.11$ \\
\hline
\end{tabular}


The data expressed as Mean $\pm \mathrm{SD}$ whereas: $* \mathrm{P}<0.1=$ significant, $* * \quad \mathrm{P}<0.01=$ highly significant and $* * * \mathrm{P}<$ $0.001=$ very highly significant. $\mathrm{Hb}=$ hemoglobin. $\mathrm{RBC}=$ red blood cells. $\mathrm{HCT}=$ haematocrit and $\mathrm{WBC}=$ white blood cells.

\section{Discussion:-}

In our results, treatment the animals with analgesic dose of Nalbuphine-HCl for thirty days were showed some histopathological changes which included hydropic degenrative changes in hepatocytes with picknotic nuclei and obliterated blood sonusoides present between the cords. The destructive changes were similarly reported in the liver tissues of rats following treatment with morphine (Atici, Cinel et al. 2005). Cytoplasmic vacuolation and ballooning of the hepatocytes which appeared after treatment of the animals with double analgesic dose of Nalbuphine-HCl. Also, picknotic nuclei, necrotical areas, congested and dilating central vein were detected in the second group animals. These results were approximately similar to Bekheet (2010) who stated that morphine exhibited proliferation and an increased inflammatory infiltration and focal parenchymal necrosis and portal fibrosis. Furthermore, Das and Ratty (1987) suggested that cocaine caused hepatic toxicity where the drug caused fatty infiltration. Also, Maha et al (1995) demonstrated that cytoplasmic vacuolation is mainly a consequence of considerable disturbance in lipid inclusion and fat metabolism occurring under pathological cases.

After treatment the animals with triple analgesic dose of Nalbuphine-HCl. Histopathological examination showed more pathological changes which included dilated congested blood and demonstrating marked stagnant blood in portal vein, inflammatory infiltration around the bile duct, vacuolated, ball owning cytoplasm with pyknotic nuclei. This may be attributed to vacuolation and swelling of most hepatic cells which may be hydropic degeneration. These results are in agreement with William et al (1991) reported that the isolated hepatocytes exhibited a marked decrease in glutathione level when incubated with various concentration of morphine and resulted in cell death (apoptotic cells). Also these results were mentioned before by Bekheet (2010). So, the cells of the periphery of the hepatic lobules are subjected to the high concentration of toxic metabolites than the middle and inner layers of the lobules. In addition, Atici et al (2005) reported that apoptotic bodies, necrotic areas, vacuolization and congested blood vessels were clear in rats liver treated with morphine. Similar result may be noticed during the present observation, where much of apoptotic cells, necrotic areas were noticed in the liver tissues of the treated animals.

The liver tissue of animals treated with Nalbuphine-HCl especially under addictive or analgesic dose showed fibrotic lesion and lymphocyte inflammatory cells indicating induction of chronic inflammatory disease. This conclusion may coincide with Al-Shinnawy (2009) who stated that chronic active fibrosis is accompanied by infiltration with inflammatory cells around the portal tract and blood vessels. The observed liver lesions during these studies were followed by an increase of the fibers around the portal tracts and bile ducts. This was mentioned before by Maha et al (1995) who reported that condensation of the stroma was a consequence following destruction of liver cells which led finally to fibrosis of liver tissues. Darkly stained pyknotic nuclei which appeared after all doses may be as a result of coiling and shortening of chromosomes which became inactive especially in protein synthesis. This result was similar to the finding of Levier et al. (1993) who found that morphine sulphate induced nuclei changes in the tissue cell of adult Mikado.

The congestion of the blood sinusoids and central veins which were nearly found in all dose of the present study may be due to the dilation in peripheral blood vessels induced by Nalbuphine- $\mathrm{HCl}$ as mentioned by Rosow et al (1982) who reported that morphine induced dilation in peripheral blood vessel. This dilation led to decreased of blood draining as well as decreases the blood velocity through the sinusoids and central vein. Also, the infiltration of the liver with erythrocytes and the elevated breakdown of affected erythrocytes may explain the proliferation of Kupffer's cells. The main functions of these cells are phagocytic (Holm and Kasper 1985). So, they play an important role in removing bacteria and toxic substances (Holm and Kasper 1985). However, the results obtained in this study showed that, Kupffer's cells were a dose and time dependent. This attributed to the fact that, Nalbuphine$\mathrm{HCl}$ produced a dose dependent decrease in hepatic phagocytosis (Levier, Brown et al. 1993). These authors explained that the hepatic phagocytic capacity returned to control level within 48 hours in mice implanted with morphine sulphate.

Data in the Table (1) showed a significant increase in the levels of liver enzymes of in (AST, ALT and ALP). These results were consistent with the histopathological, which may explain the toxicity effects of Nalbuphine-HCl, on the rat's hepatic tissues. Our results in agreement with many studies demonstrated that effects of Nalbuphine-HCl (ElBakry, Kandil et al. 1995, Al-Shinnawy 2009). Also, Borzelleca et al (1994) who demonstrated that increase levels 
of ALT, AST and LDH in rats after the treatment with high doses of levo-alpha-acetylmethadol hydrochloride (LAAM), a long-acting morphine-like (mu). In addition, our results in agreement with Maha et al (1995) who reported that, increase levels serum of ALT, AST in rats due to treated with morphine and tramadol for long term period.

On the other hand, results of $\mathrm{CBC}$ of hemoglobin, red blood cells, haematocrit and platelets in the all treated groups with analgesic, double and triple analgesic doses of Nalbuphine- $\mathrm{HCl}$ showed a significant decreased in comparison to those of the control group showed in data in the Table (2). These results are consistent with those of Al-Shinnawy (2009) who explained that reduction of hemoglobin, blood cell count and haematocrit is due to Nalbuphine- $\mathrm{HCl}$ may prevent red blood cell synthesis via inhibition of erythropoiesis in the bone marrow which leads to microcytic hypochromic anemia also our results were in agreement with Al-Shinnawy (2009) who attributed that microcytic hypochromic anemia may be due to treatment with Nalbuphine- $\mathrm{HCl}$ has consequence effect on bone marrow, spleen and liver and decrease of hemoglobin due to extravasation of blood and haemolysis of red blood cells. Whereas, hematological results of WBCs value showed no significant changes in its value of these result. these results was in agreement with Shinnawy (2009) who attributed that Nalbuphine- $\mathrm{HCl}$ has no significant changes of total leucocyte count in its value in the experimental animals which treated with Nalbuphine-HCl.

\section{Summary:-}

The main histopathologic results of this study showed inflammatory cellular infiltration, dilated congested blood vessels, hydropic degeneration, and fibrotic regions around the proliferated bile ducts in the hepatic tissues. On the other hand, the biochemical results of the liver enzymes (AST, ALT and ALP) and the hematological investigation ( $\mathrm{Hb}, \mathrm{RBC}$ HCT and the platelets cells) were revealed marked decrease in liver enzymes and hematological parameters. The biochemical and hematological results were parallel to the histopathological changes after all doses (analgesic, double and/or triple analgesic) treatment of Nalbuphine-HCl, which may explain the toxic effects of Nulbuphine- $\mathrm{HCl}$ on the hepatic tissue.

\section{References:-}

1. Al-Shinnawy, M. (2009). " Effect of nalbuphine (A narcotic Drug) on some hematological and biochemicals parameters of male albino rat." Egyptian journal of hospital medicine 34: 143-154

2. Alsbery, A. Y. A. a. H. M. A. E. (2016). "Evaluation of the Hepatoprotective Efficacy of Moringa oleifera on Tramal-Induced Liver Toxicity in Animal Modules." Research Journal of Pharmaceutical, Biological and Chemical Sciences 7(5): 1494.

3. Atici, S., I. Cinel, L. Cinel, N. Doruk, G. Eskandari and U. Oral (2005). "Liver and kidney toxicity in chronic use of opioids: an experimental long term treatment model." J Biosci 30(2): 245-252.

4. Attia, J. Z., M. Y. Kamel and R. K. Yousef (2015). "Safety of nalbuphine on neural tissues of rats and its efficacy in the treatment of acute herpetic pain in children with acute lymphoblastic leukemia." Research and Opinion in Anesthesia and Intensive Care 2(3): 89.

5. Bancroft, J. D. and M. Gamble (2008). Theory and practice of histological techniques, Elsevier Health Sciences.

6. Bekheet, S. H. (2010). "Morphine sulphate induced histopathological and histochemical changes in the rat liver." Tissue and Cell 42(4): 266-272.

7. Borzelleca, J. F., J. L. Egle, Jr., L. S. Harris, D. N. Johnson, J. B. Terrill and J. A. Belleville (1994). "Toxicological evaluation of mu-agonists. Part I: Assessment of toxicity following 30 days of repeated oral dosing of male and female rats with levo-alpha-acetylmethadol HCl (LAAM)." J Appl Toxicol 14(6): 435-446.

8. Chen, K.-T., O. Hu, S.-T. Ho, Y.-W. Chen and J.-J. Wang (2002). "The analgesic effect of nalbuphine and its long-acting prodrug, nalbuphine pivalate, in rats." Acta anaesthesiologica Sinica 40(4): 191-195.

9. Chu, K.-S., J.-J. Wang, O. Y.-P. Hu, S.-T. Ho and Y.-W. Chen (2003). "The antinociceptive effect of nalbuphine and its long-acting esters in rats." Anesthesia \& Analgesia 97(3): 806-809.

10. Clough, G. (1982). "Environmental effects on animals used in biomedical research." Biological Reviews 57(3): 487-523.

11. Daniel, S. and M. Marshall (1999). Evaluation of the liver: laboratory tests. Schiff's diseases of the liver, USA.

12. Das, N. P. and A. K. Ratty (1987). "Studies on the effects of the narcotic alkaloids, cocaine, morphine, and codeine on nonenzymatic lipid peroxidation in rat brain mitochondria." Biochemical medicine and metabolic biology 37(2): 258-264. 
13. El-Bakry, M., W. Kandil, M. El-Harouny, M. Sultan and W. El-Sankary (1995). "HISTOPATHOLOGICAL AND HAEMATOLOGICAL CHANGES INDACED BY DIFFERENT DOSES OF NALBUPHINE VERSAS MORPHINE ON ALBINO RATS." MJFMCT, Vol.3, No. 1,lan. 1995 3(1): 109.

14. Gerak, L. R., E. R. Butelman, J. H. Woods and C. P. France (1994). "Antinociceptive and respiratory effects of nalbuphine in rhesus monkeys." Journal of Pharmacology and Experimental Therapeutics 271(2): 993-999.

15. Holm, E. and H. Kasper (1985). Metabolism and nutrition in liver disease, Springer Science \& Business Media.

16. Levier, D. G., R. D. Brown, J. A. McCay, B. A. Fuchs, L. S. Harris and A. E. Munson (1993). "Hepatic and splenic phagocytosis in female B6C3F1 mice implanted with morphine sulfate pellets." J Pharmacol Exp Ther 267(1): 357-363.

17. Liaqat, N. and S. H. Dar (2016). "Comparison of single-dose nalbuphine versus tramadol for postoperative pain management in children: a randomized, controlled trial." Korean Journal of Anesthesiology 69.

18. Lutz, P. and W. Dzik (1993). "Large-volume hemocytometer chamber for accurate counting of white cells (WBCs) in WBC-reduced platelets: validation and application for quality control of WBC-reduced platelets prepared by apheresis and filtration." Transfusion 33(5): 409-412.

19. Mescher, A. L. (2013). Junqueira's basic histology: text and atlas, Mcgraw-hill.

20. Miller, R. R. (1980). "Evaluation of nalbuphine hydrochloride." Am J Hosp Pharm 37(7): 942-949.

21. Pacifici, G., C. Bencini and A. Rane (1986). "Presystemic glucuronidation of morphine in humans and rhesus monkeys: subcellular distribution of the UDP-glucuronyltransferase in the liver and intestine." Xenobiotica 16(2): 123-128.

22. Pick, C. G., D. Paul and G. W. Pasternak (1992). "Nalbuphine, a mixed kappa 1 and kappa 3 analgesic in mice." Journal of Pharmacology and Experimental Therapeutics 262(3): 1044-1050.

23. Rosow, C. E., J. Moss, D. M. Philbin and J. J. Savarese (1982). "Histamine release during morphine and fentanyl anesthesia." Anesthesiology 56(2): 93-96.

24. Walker, E. A., E. Butelman, B. DeCosta and J. Woods (1993). "Opioid thermal antinociception in rhesus monkeys: receptor mechanisms and temperature dependency." Journal of Pharmacology and Experimental Therapeutics 267(1): 280-286.

25. William, S., N. Sekar, S. Subramanian and S. Govindasamy (1991). "Toxic effect of morphine and the antagonistic role of naloxone on isolated rat hepatocytes." Biochem Int 23(6): 1071-1077. 